\title{
Formação de Técnico em Agropecuária no Brasil e na Espanha: Projetos de vida da juventude rural
}

\author{
Formation of Agricultural Technicians in Brazil and Spain: Rural youth life \\ projects
}

\author{
Jorge Luiz de Goes Pereira ${ }^{1}$ (D), Fátima Cruz Souza² (D) \\ ${ }^{1}$ Instituto de Agronomia, Programa de Pós-graduação em Educação Agrícola (PPGEA), Universidade Federal Rural do Rio de \\ Janeiro (UFRRJ), Rio de Janeiro (RJ), Brasil. E-mail: jolugope@uol.com.br \\ ${ }^{2}$ Departamento de Psicología, Catedra de Estudos de Género, Universidad de Valladolid (UVA), Palencia, Espanha. E-mail: \\ fatimaregina.cruz@uva.es
}

\begin{abstract}
Como citar: Pereira, J. L. G. \& Souza, F. C. (2020). Formação de Técnico em Agropecuária no Brasil e na Espanha: Projetos de vida da juventude rural. Revista de Economia e Sociologia Rural, 58(4), e202404. https://doi.org/10.1590/1806-9479.2020.202404.
\end{abstract}

Resumo: Esse artigo discute a articulação entre gênero, educação técnico-profissional em Agropecuária e projetos de vida de moças e rapazes rurais dos Institutos Federais de Educação, Ciência e Tecnologia do norte do Brasil e dos Centros de Formación Agrária do norte da Espanha. Trata-se de um estudo exploratório-descritivo realizado com método misto. Utilizou-se como instrumento de pesquisa um questionário com 22 questões abertas e 12 questões fechadas que foram respondidas por 197 participantes (142 brasileiros e 55 espanhóis), sendo 130 rapazes e 67 moças. Para garantir a validez dos resultados, o processo de triangulação completou-se com entrevistas em profundidade a gestores educacionais (dois brasileiros e dois espanhóis) e dois jovens rurais. Os dados quantitativos foram analisados com procedimentos de estatística descritiva, enquanto os dados qualitativos foram categorizados seguindo o processo de codificação temática. Os resultados mostram uma vinculação entre a formação profissional técnica e os projetos de vida dos jovens estudantes, com uma forte diferença marcada por gêneros, e que a opção por uma formação agropecuária entre jovens brasileiros tem uma função instrumental de abrir possibilidades de acesso a outros cursos ou outras áreas de formação, enquanto os rapazes espanhóis estão mais claramente vinculados familiarmente com as atividades agrícolas.

Palavras-chave: Juventude Rural, formação técnica em agropecuária, projeto de vida, gênero.

\begin{abstract}
This paper aims to discuss the articulation among gender, technical-professional education in Agriculture and life projects of rural youth in the Institutos Federais de Educação, Ciência e Tecnologia in the north of Brazil and the Centros de Formación Agraria in the north of Spain. This is an exploratory-descriptive study, which was carried out by mixed methods. A questionnaire with 22 open and 12 closed questions was answered by 130 male and 67 female participants (142 Brazilians and 55 Spaniards). Furthermore, four in-depth interviews with school administrators (02 Brazilians and 02 Spaniards) and two with rural youngsters were carried out for data triangulation to verify and validate the gathered information. Quantitative data were analyzed by descriptive statistics procedures, while qualitative data categorization followed the thematic coding process. The results show a link between technical vocational training and the life projects of young students, with a strong difference marked by gender, and the option for agricultural training among young Brazilians has an instrumental function of opening possibilities for access to other courses or other areas of training, while Spanish boys are more clearly familiarly related to agricultural activities.
\end{abstract}

Keywords: Rural Youth, technical training in agriculture, life project, gender.

\section{Introdução}

Os estudos sobre juventude rural no Brasil (Lopes \& Carvalho, 2015; Stropasolas, 2006, 2014; Castro, 2009; Carneiro \& Castro, 2007; Pereira, 2004; Abramovay et al.,1998, entre outros) e na Espanha (Camarero et al., 2016, 2009; Cruz, 2006, entre outros) apontam alguns motivos para um esvaziamento do campo, principalmente marcado pela saída das mulheres 
jovens. Nesses países, assim como em outros com forte vocação agrícola, observa-se um processo que parece atingir o mundo rural cujas fronteiras rural/urbano cada vez mais vão diminuindo, aproximando comportamentos socioculturais de ambos os espaços, e a juventude, em processo de construção de seus projetos de vida e de formação profissional, representa a maior expressão desse processo.

As tendências de industrialização e concentração de mão de obra nas cidades, assim como os efeitos massivos do processo de globalização econômica e cultural, são similares tanto na Espanha como no Brasil, variando sim as características especificamente locais dos fenômenos e os ritmos das transformações. No caso brasileiro, as limitadas oportunidades de trabalho, educação e lazer no meio rural, assim como as dificuldades enfrentadas pela baixa infraestrutura de circulação e transporte, de acesso à informação, de energia elétrica, entre outras, empurram os jovens para os espaços urbanos, muitas das vezes com apoio dos pais, como estratégia de reprodução social de todo o grupo familiar. Qualquer esperança de sucesso pessoal e profissional aparece vinculada às possibilidades de vida urbana. Moças e rapazes estão projetando seu futuro suscetíveis às mudanças em curso no meio rural. No caso específico das moças, elas se identificam cada vez menos com os tradicionais papéis de gênero, diversamente das gerações passadas. Buscam construir trajetórias de vida diferentes de suas mães e avós, inclusive animadas por elas, muitas analfabetas e sem formação profissional, para atuarem em áreas específicas dentro e fora da agricultura.

$\mathrm{Na}$ Espanha, por sua vez, segundo Benito \& Mendez (2009), as transformações que ocorreram a partir da metade dos anos 1980 e começo do século XXI, com a diluição das fronteiras entre rural e urbano, geraram uma sociedade cada vez mais integrada e mais móvel, ao mesmo tempo em que se debilitam os limites geográficos e, sobretudo, socioculturais da dita distinção rural/urbano. As fronteiras entre campo e cidade se diluem, prevalecendo os valores de uma sociedade urbanoindustrial como referências na construção dos projetos de vida da juventude rural (Camarero et al., 2009).

Os povoados espanhóis com tradição agrícola têm visto diminuir o seu número de habitantes, uma vez que a atratividade dos centros urbanos ou de atividades não agrícolas próximas às comunidades rurais, tais como as industriais, representam possibilidades de uma melhor remuneração para os/as jovens, principalmente para aqueles e aquelas que conseguem um nível educacional melhor (Benito \& Mendez, 2009). Num estudo realizado com jovens rurais, Cruz (2006) ressalta que todas as estudantes de Ensino Médio entrevistadas por ela já possuíam um projeto para emigrar do meio rural por meio dos estudos posteriores e suas representações do rural relacionadas com "agrário" expressavam a dureza do trabalho agrícola e a rejeição a trabalhar na agricultura e na pecuária.

Mas aqui, assim como em partes do Brasil, também a diluição das fronteiras rural/urbano e as alterações no processo produtivo (atividades agrícolas altamente mecanizadas) ou na reprodução biológica das famílias (diminuição do número de filhos) atingem não somente as mulheres, mas toda a juventude, já que, indiferentemente, moças e rapazes buscam atividades remuneradas fora do espaço agrícola familiar (Benito \& Mendez, 2009).

Além disso, a juventude rural espanhola vem enfrentando um forte processo de recessão econômica e desemprego, e se sente menos atraída pelas atividades rurais. Essa desagrarização dos territórios rurais tem levado moças e rapazes a ingressarem no setor de serviços, setor que mais cresce na Região Autónoma de Castilla y León, ademais contribui para a masculinização e o envelhecimento no meio rural, fazendo com que a juventude rural crie estratégias para permanecer ou sair do campo. Essa realidade, em nada difere do rural brasileiro.

O objetivo deste artigo é discutir a articulação entre educação técnico-profissional em Agropecuária e os projetos de vida de moças e rapazes rurais dos Institutos Federais de Educação, Ciência e Tecnologia (IFs) do norte do Brasil e dos Centros de Formación Agrária do norte da Espanha, além de analisar a relação do vínculo dos jovens estudantes com atividades agrícolas, seus interesses e as diferenças de gênero na formação profissional. Assim, analisamos o papel de instituições de diferentes países de vocação agrícola no acesso e na permanência dos jovens rurais nos cursos técnicos em Agropecuária. 
Nos apropriamos aqui do conceito de andaimagem de Jerome Bruner (Wood et al., 1976), quando o autor faz referência à importância do papel que pessoas mais experientes e, por que não dizer, instituições de ensino podem desempenhar no processo de aprendizagem daqueles e daquelas menos experientes na sua formação identitária e profissional. No caso da educação técnico-profissional para o mundo rural, o processo de andaimagem pode contribuir no fortalecimento das identidades rurais dos jovens ao integrá-las à vida profissional, assim como nas novas significações da ruralidade dos jovens, com uma (re)valorização das características socioculturais e estéticas da vida no campo. Portanto, o rural se relaciona com as possibilidades de futuro dos jovens e ambos são parte fundamental dos projetos educacionais desenvolvidos pelas instituições de ensino técnico-profissionalizante.

Entendemos gênero como uma construção social baseada em marcas corporais que historicamente estabelece uma hierarquia e uma relação de dominação do masculino sobre o feminino (Harding, 1996; Lagarde, 1996; Scott, 1986, entre outras). Como afirma Lagarde (1996), "cada pessoa é ensinada a ser mulher ou ser homem de diversas maneiras e por diferentes pessoas, instituições e meios..." (p.47). Nesse sentido, as instituições educacionais podem reforçar a ideia de universos distintos e hierarquizados entre homens e mulheres ou contribuir para mudanças nessas relações de poder. No caso da formação profissional na área de agrárias, de modo geral, essa parece contemplar mais facilmente o interesse dos rapazes, pois o rural é percebido como um lugar naturalmente masculino, no qual as mulheres são vistas como intrusas ou como ajudantes dos legítimos protagonistas, que são os homens.

\section{Formação agrária e projetos de vida da juventude rural}

Buscar uma profissão é, na verdade, uma mistura de realização pessoal e coletiva (familiar), e dependerá do campo de possibilidades que se constitui em torno de cada um dos sujeitos (Velho, 1987), isto é, a realização de um projeto de futuro como a aquisição de uma profissão vai depender do campo de possibilidades a que cada pessoa tem e terá acesso no decorrer de sua vida. Esse campo pode se ampliar ou se reduzir de acordo com as relações sociais que se estabelecem no tempo e no espaço. Para os/as jovens, é um momento de grandes dilemas e incertezas, pois a escolha de uma profissão não é um ato simples, uma aventura, é antes de tudo uma decisão que envolve muitos elementos e que se direciona para a realização pessoal.

Por outro lado, deve-se levar em consideração que o momento da juventude pode ser considerado como uma etapa do ciclo de vida na qual se constroem muitas e novas experiências, novas expectativas. Não existe uma homogeneidade identitária ou cultural nesse momento da vida dos sujeitos que chamamos de juventude. Como salienta Stropasolas (2006), aquilo que definimos como juventude, simplesmente "unifica simbolicamente um grupo que é composto diversamente, que encobre realidades socialmente diversificadas" (p. 180).

E, no caso da juventude rural, esta deve ser compreendida na sua dupla dinâmica social, tendo em vista se tratar de uma categoria que está inserida numa dinâmica territorial que envolve a casa (relações familiares), a vizinhança (relações de comunidade) e a cidade (relações com o mundo urbanoindustrial), assim como a dinâmica temporal, marcada pelas relações com as tradições familiares e de parentesco, e que, por sua vez, orientam suas práticas e estratégias atuais e de futuro (Carneiro \& Castro, 2007). Assim, mesmo entre os jovens rurais, há muitas formas de ser e viver esse momento da vida, pois, ainda que inseridos em um mesmo território, poderemos encontrar diferentes "juventudes rurais", possibilidades e oportunidades diferenciadas para moças e rapazes.

Já Lopes \& Carvalho (2015) colocam que é preciso que observemos os diferentes contextos em que os jovens rurais estão inseridos na atualidade e as transformações que vêm ocorrendo na sociedade rural. Transformações, tais como:

[...] a diversificação das atividades produtivas, para além da agrícola; maior integração do rural com o urbano; transformações dos estilos de vida e valores; melhoria da mobilidade geográfica, e descentralização da política administrativa (Lopes \& Carvalho, 2015, p.573). 
Diante dessas transformações, os jovens são os mais suscetíveis aos processos migratórios em direção à cidade, já que são mais permeáveis à propaganda da sociedade de consumo e buscam melhorar suas condições de vida, uma vez que eles enfrentam problemas de exclusão social mais intensos que os adultos (Jurado \& Tobasura, 2012) e têm menos responsabilidades adquiridas que limitem sua mobilidade.

Portanto, os estudos sobre juventude representam, nesse sentido, um desvelamento dessas diferentes juventudes, enfocando suas especificidades ligadas às questões de tempo e espaço, de gênero, etc. Como nos coloca Bourdieu (1996), não é suficiente apontar a existência das diferenças, mas é preciso mostrar como elas acontecem e a partir de que estruturas e relações elas se desenvolvem.

É ao que nos propomos aqui, ao observar o processo de construção dos projetos de vida da juventude rural no Brasil e na Espanha, a partir de sua inserção nos cursos de formação técnica em Agropecuária, com uma leitura de gênero. Partimos do pressuposto de que novos significados estão sendo produzidos com o acesso dos jovens à educação profissional. Em muitos casos, a agricultura e o local de origem já não são as únicas referências a incidir sobre as identidades dos jovens e seus desejos de futuro. Mesmo para aqueles e aquelas, aos quais a agricultura permanece como a atividade principal, outros espaços vêm ampliando seu processo de socialização, seja no contato com os espaços urbanos, seja no contato com outros jovens e outras profissões. A juventude rural, ao romper as fronteiras culturais entre campo e cidade, traz novos sentidos para suas identidades sociais, seus projetos de vida, em que a permanência nas atividades rurais nem sempre é desejada, mesmo que o viver no campo ainda seja sua referência principal.

Na pesquisa sobre a diluição das fronteiras campo/cidade (Pereira, 2004), as localidades rurais pesquisadas aparecem como realidades objetivadas, isto é, são representações ${ }^{1}$ ancoradas nas suas práticas sociais, mas também são parte dos discursos hegemônicos de poder e que, portanto, fazem parte das estruturas mentais e afetivas. Às vezes, podem aparecer deslocadas das práticas, mas isso faz parte da própria dinâmica entre práticas e representações sociais, como aponta Bozon (1995), quando analisa o sentido da identidade social. Segundo ele, as práticas são mais dinâmicas que as representações sociais, porque estão em constante processo de mudança, já que fazem parte da vida dos indivíduos em sociedade, forçando as representações a acompanharem essa dinâmica social. Assim, ao mesmo tempo em que querem ser iguais, os/as jovens das localidades rurais reforçam a ideia de que são diferentes.

Portanto, é preciso compreender a multiplicidade das identidades sociais em discussão, a relação existente entre diferentes espaços, o sentido que tomam o desejo de futuro dos jovens. Além disso, é preciso levar em consideração que a construção de projetos individuais dependerá da interação com outros projetos competitivos, como, por exemplo, os projetos familiares, que podem ir na mesma direção ou serem percebidos como antagônicos.

Hernández (2000) entende por projeto de vida, por um lado, como sendo a formação psicológica integradora da pessoa em direções vitais principais que, segundo o autor, envolvem suas relações sociais (trabalho, profissão, família, tempo livre, atividade cultural, sociopolítica, relações de amizade e afetivas, organizacionais, entre outras), e, por outro lado, como sendo a expressão do funcionamento de diferentes mecanismos e formações psicológicas que integram todo o campo da experiência pessoal.

Portanto, "projeto de vida", antropologicamente, está imbricado com a ideia de "campo de possibilidades". Velho (1987), partindo do pressuposto de que o indivíduo tem uma dimensão culturalmente construída, que é acrescentada ao agente empírico, afirma que a existência de projetos individuais está vinculada a contextos socioculturais específicos, lidando-se assim com a ambiguidade fragmentação-totalização. Barros et al. (2015) identificam quatro elementos fundamentais para a estruturação dos projetos de vida: as relações familiares, as relações com a sociedade, as relações com o trabalho e as relações

\footnotetext{
${ }^{1}$ A "representação social" expressa uma forma de conhecimento que, por ser socialmente construída, permite ao indivíduo elaborar uma visão de mundo que o oriente em projetos de ação e nas estratégias que desenvolve em seu meio social. E ainda, que por serem culturalmente carregados, adquirem sentido e significado pleno apenas quando levado em consideração o contexto em que se manifestam (QUEIROZ, 2003).
} 
com o conhecimento. Dessa forma, o projeto individual nunca é puro, mas existe referido ao outro, ao social, principalmente à família e às relações de parentescos, mas também nas relações e experiências de contato com o mundo do trabalho, da educação formal e de exploração/ampliação das próprias habilidades e capacidades nos processos de formação, aprendizagem e de reconhecimento do mundo.

Neste sentido, o acesso à escola pode funcionar como a ampliação do campo de possibilidades para a juventude. Os projetos de vida da juventude rural parecem caminhar na direção na qual o vivido e o percebido se aliam aos desejos de quererem ser, ao mesmo tempo, iguais a e diferentes de seus pais, parentes e amigos, e também iguais a e diferentes de seus pares urbanos. A educação rural pode funcionar como espaço para a identificação dos jovens e o fortalecimento das atividades rurais, ao colocar suas experiências dialogicamente à disposição dos educandos. Contudo, as características da sociedade urbanoindustrial continuam servindo de referência urbano-normativa na construção de seus projetos de vida, assim como as transformações do mundo do trabalho com o neoliberalismo de consumo e não mais de produção (Bauman, 2000), e as condições de gênero, que podem exercer forte papel nas escolhas individuais (Cruz, 2006).

\section{Metodologia}

Trata-se de um estudo exploratório-descritivo (documental, interpretativo e analítico), realizado com método misto (Greene, 2007, 2008) sobre os/as jovens regularmente matriculados nos cursos técnico-profissionalizantes da área de agrárias no Brasil, região Norte, e na Espanha, nas províncias de Valladolid e Palencia na região de Castilla y León. Utilizou-se como instrumento de levantamento de dados um questionário com 34 questões (22 questões abertas e 12 fechadas), não identificável o informante, recebendo posteriormente um número de controle para tabulação. O questionário consta de cinco blocos de perguntas (Dados socioeconômicos; Da localidade onde mora; Da escolha do curso da área de agrárias; Sobre a formação e projetos de vida; Juventude e gênero).

Ao todo, foram respondidos 197 questionários (142 participantes brasileiros e 55 espanhóis), sendo 130 rapazes e 67 moças. Desse universo, 130 participantes se autoidentificaram como urbanos e 67 como rurais (31 brasileiros e 36 espanhóis), majoritariamente do sexo masculino (54 rapazes e 13 moças), na faixa etária entre 14 e 24 anos, e matriculados entre o primeiro e o terceiro ano, conforme o Quadro 1.

Quadro 1 - Perfil dos/das jovens participantes

\begin{tabular}{|c|c|c|c|c|c|c|c|}
\hline \multirow{2}{*}{ INSTITUTO } & \multicolumn{3}{|c|}{ ESCOLARIDADE } & \multirow{2}{*}{$\begin{array}{c}\text { FAIXA- } \\
\text { ETÁRIA } \\
\text { (14 A 18) }\end{array}$} & \multirow{2}{*}{$\begin{array}{l}\text { FAIXA- } \\
\text { ETÁRIA } \\
\text { (19 A 24) }\end{array}$} & \multirow{2}{*}{ RURAL } & \multirow{2}{*}{ URBANO } \\
\hline & $1^{\circ}$ & $2^{\circ}$ & $3^{\circ}$ & & & & \\
\hline \multicolumn{8}{|l|}{ IFAM } \\
\hline Masculino & 0 & 10 & 15 & 17 & 8 & 1 & 24 \\
\hline Feminino & 0 & 6 & 11 & 13 & 4 & 2 & 15 \\
\hline \multicolumn{8}{|l|}{ IFAP } \\
\hline Masculino & 34 & 0 & 0 & 34 & 0 & 5 & 29 \\
\hline Feminino & 28 & 0 & 0 & 28 & 0 & 4 & 24 \\
\hline \multicolumn{8}{|l|}{ IFRR } \\
\hline Masculino & 0 & 0 & 23 & 12 & 11 & 14 & 9 \\
\hline Feminino & 0 & 0 & 15 & 11 & 4 & 5 & 10 \\
\hline TOTAL 1 & 62 & 16 & 64 & 115 & 27 & 31 & 111 \\
\hline
\end{tabular}




\begin{tabular}{|c|c|c|c|c|c|c|c|}
\hline \multirow{2}{*}{ Quadret!rtcrontir } & \multicolumn{3}{|c|}{ ESCOLARIDADE } & \multirow{2}{*}{$\begin{array}{l}\text { FAIXA- } \\
\text { ETÁRIA } \\
\text { (14 A 18) }\end{array}$} & \multirow{2}{*}{$\begin{array}{l}\text { FAIXA- } \\
\text { ETÁRIA } \\
\text { (19 A 24) }\end{array}$} & \multirow{2}{*}{ RURAL } & \multirow{2}{*}{ URBANO } \\
\hline & $1^{\circ}$ & $2^{\circ}$ & $3^{\circ}$ & & & & \\
\hline \multicolumn{8}{|l|}{$\begin{array}{c}\text { CIFP LA SANTA } \\
\text { ESPINA }\end{array}$} \\
\hline Masculino & 26 & 0 & 0 & 19 & 7 & 20 & 6 \\
\hline Feminino & 1 & 0 & 0 & 0 & 1 & 0 & 1 \\
\hline \multicolumn{8}{|l|}{ CIFP VIÑALTA } \\
\hline Masculino & 16 & 6 & 0 & 11 & 11 & 14 & 8 \\
\hline Feminino & 1 & 5 & 0 & 1 & 5 & 2 & 4 \\
\hline TOTAL 2 & 44 & 11 & 0 & 31 & 24 & 36 & 19 \\
\hline $\begin{array}{l}\text { TOTAL GERAL } \\
\quad(1+2)\end{array}$ & 106 & 27 & 64 & 146 & 51 & 67 & 130 \\
\hline
\end{tabular}

Fonte: Dados da pesquisa.

No Brasil, os estudantes pertenciam aos cursos Técnicos do Ensino Médio em Agropecuária dos IFs da Região Norte - Instituto Federal do Amazonas (IFAM, campus Maués), Instituto Federal do Amapá (IFAP, campus Porto Grande) e Instituto Federal de Roraima (IFRR, campus Novo Paraíso). Foram realizadas também entrevistas em profundidade com dois gestores dessas instituições. A aplicação dos questionários ocorreu em dezembro de 2016 e as entrevistas com os gestores, no decorrer de toda pesquisa, foram realizadas por telefone.

No norte da Espanha, Região Autônoma de Castilla y León, responderam ao questionário estudantes do ensino médio em Técnico Agropecuário de dois centros de formação agrária. São eles: Centro Integrado de Formación Profesional "La Santa Espina" e Centro Integrado de Formación Profesional "Viñalta". Também realizamos entrevistas em profundidade com dois estudantes que se autoidentificaram como de origem rural e com dois gestores. Nota-se que, nessas instituições espanholas, o número de moças é menor que nas do Brasil (apenas oito moças), um dado relevante e que discutiremos no decorrer das análises. O contato com essas instituições se deu através da Faculdad de Educación de Palencia da Universidad de Valladolid e o acesso aos estudantes foi facilitado por seus gestores. O levantamento de dados nas instituições espanholas ocorreu nos meses de abril e maio de 2017.

A autoidentificação é, portanto, uma estratégia no sentido de que são os/as jovens que se definem como rurais ou urbanos, não se limitando a definições geopolíticas e econômicas de órgãos oficiais do Brasil e da Espanha, pois temos a convicção de que tais definições não dão conta dos universos pesquisados, pois os espaços, mais do que físicos, são também - e principalmente - espaços socioculturais. Assim, dependendo de como esses espaços são vivenciados pelos jovens, eles e elas podem reforçar sua autoindentificação com o mundo rural ou mesmo negá-lo, tentando se afastar de imagens negativas que possam servir de referência na relação com seus amigos na escola, no trabalho ou em qualquer outro espaço social.

A pesquisa contou também com informações referentes aos modelos de educação profissionalizante na área de agrárias adotados pelas instituições em ambos os países e que estão disponíveis na internet (projeto pedagógico, programa de curso, processo seletivo, etc.), em sites institucionais, como do Ministério da Educação do Brasil e do governo regional de Castilla y León, na Espanha. Entretanto, não é nossa intenção aqui discutir os Projetos Pedagógicos de Curso (PPC), os programas analíticos das disciplinas e as metodologias adotadas pelas diferentes instituições, mas analisar como os jovens percebem sua relação com as instituições e o que elas são capazes de oferecer para a concretude dos seus projetos de vida. 
É preciso destacar ainda dois fatos que nos ajudaram na análise dos dados levantados. Em primeiro lugar, o fato da diferença no número de questionários aplicados em cada país está diretamente relacionado à diferença do número de alunos disponíveis em cada Instituição pesquisada na época do levantamento, não seguindo a priori a necessidade de um universo amostral significativo por não se tratar de uma pesquisa comparativa, mas de cunho exploratório, de forma a compreender as experiências de moças e rapazes sobre os temas tratados. Em cada instituição, os questionários foram aplicados em turmas indicadas por seus responsáveis de forma a não comprometer as atividades pedagógicas de cada uma delas. Em segundo lugar, as instituições pesquisadas encontram-se em regiões de grande vocação agrícola, envolvendo jovens inseridos na agricultura familiar.

Partimos também dos pressupostos de que a juventude, assim como "gênero", é uma construção social e de que cada contexto sociocultural imprime aquilo que se define como juventude por diferentes ritos de passagem. Assim, geração e gênero estão intimamente relacionados historicamente, e a escolha do recorte etário de 14 aos 24 anos para a juventude brasileira e de 16 a 24 anos para a juventude na Espanha, nesta pesquisa, se deu tão somente porque há diferenças nas estruturas de ensino por países e nessa faixa etária, moças e rapazes estarão cursando o Ensino Médio (Brasil) ou a Educação Secundária (Espanha) na formação técnica, apesar da diferença no tempo que cada juventude leva para se formar em seus respectivos países, sendo o tempo mínimo exigido no Brasil superior ao da Espanha, como veremos mais abaixo.

Além disso, é preciso destacar que, como categoria relacional, não há essencialismo na definição de juventude, devendo ser compreendida à luz das relações que estabelece com seu entorno, historicamente referendado. Assim, falar de "juventude rural", por exemplo, representa apenas um recorte analítico contextualizado, buscando-se entender suas especificidades diante dos imponderáveis da vida, seu momento e movimento, suas falas, suas práticas e seus desejos.

Quanto às características socioeconômicas de cada região pesquisada, podemos observar que, na região Norte do Brasil, a economia é impulsionada pelo extrativismo (látex, açaí, madeira, castanha, etc.), que envolve principalmente agricultores familiares (trabalhadores rurais, posseiros e arrendatários), e pela mineração de baixa tecnologia, destacando-se o Polo Industrial de Manaus, que apresenta mais de quinhentas indústrias de variados segmentos (eletroeletrônico, químico, informática, fabricação de motos, bicicletas, alimentício, etc.).

Trata-se de uma região onde uma parte importante da população vive em condições socioeconômicas precárias, principalmente das Comunidades Ribeirinhas (populações que vivem às margens ou sobre os rios da região) e dos Povos Indígenas. A região Norte apresenta a maior população indígena do Brasil. Os Povos Indígenas estão presentes nas cinco regiões do Brasil, sendo que a região Norte é aquela que concentra o maior número de indivíduos 342,8 mil -, principalmente na Amazônia, e o menor na região Sul, 78,8 mil (Instituto Brasileiro de Geografia e Estatística, 2010).

Os dados do Instituto Brasileiro de Economia e Estatística (Instituto Brasileiro de Geografia e Estatística, 2010) informam que as regiões Norte e Nordeste enfrentam muitos problemas relacionados com deficiente infraestrutura das estradas que ligam as capitais ao interior dos estados, principalmente nas áreas rurais; falta de transporte público; falta de usinas de tratamento de resíduos e de água potável; alto déficit de saneamento básico nas residências e de condições adequadas de saúde pública, o que reflete diretamente nas altas taxas de mortalidade infantil, acima de 23,5 óbitos a cada mil nascidos vivos (a segunda maior média do país); o baixo número de escolas dos Ensinos Fundamental e Médio com condições adequadas de funcionamento, principalmente no campo, além dos problemas de criminalidade e de desemprego que atingem principalmente jovens entre 14 e 25 anos, do sexo masculino, negros e pardos².

\footnotetext{
${ }^{2}$ Segundo dados do CGIAE/Ministério da Saúde (Brasil, 2017a), as regiões brasileiras Norte e Nordeste apresentaram os maiores aumentos em casos de mortes violentas entre 2000 e 2015, sendo Belém a região onde se verifica o maior aumento, seguida por Manaus. As mortes estão ligadas à falta de aparatos do Estado (educação, saúde, segurança pública e acesso ao mercado de trabalho).
} 
Essa região também é conhecida pelos seus casos históricos de violência no campo, envolvendo meeiros, indígenas e grandes proprietários de terra, que ganham o noticiário brasileiro todos os dias. O Índice de Desenvolvimento Humano (IDH) de 2015, divulgado em 2016 pelo Programa das Nações Unidas para o Desenvolvimento (PNUD), informa que os estados nortistas, onde estão os Institutos pesquisados, são: Roraima - 0,757, Amapá - 0,753 e Amazonas - 0,719, mostrando que as populações desses estados estão inseridas em contextos de grande vulnerabilidade socioeconômica.

Em relação à região norte da Espanha, a Região Autónoma de Castilla y León possui $94.227 \mathrm{~km}^{2}$, apresenta uma baixa densidade populacional de 27,4 habitantes por $\mathrm{km}^{2}$ (EUR-Lex, 2014), sendo que a maior parte se concentra nas capitais de províncias, deixando o meio rural com densidades de população consideradas de deserto humano. Basicamente, a atividade econômica da região é formada por empresas familiares (95\%) consideradas microempresas, sendo que $68 \%$ operam na área de serviços, $16 \%$ na área de indústria, $8 \%$ na construção e somente $8 \%$ na agricultura.

Tradicionalmente, a região é produtora de cereais, de gado leiteiro e de corte, e de vinho. Entretanto, os setores de serviços e industrial possibilitam as maiores oportunidades de empregabilidade, apesar da importância da agropecuária para o País. Segundo o Organização das Nações Unidas (2016), a Espanha possui um IDH de 0,876, sendo que a Região Autónoma de Castilla y León está acima da média nacional, com um índice de 0,902. Um dos motivos apontados para que a Espanha apresente um dos melhores IDH entre os 188 analisados pela ONU, situada na 26 . $^{a}$ posição no ranking, está relacionado ao seu ótimo nível educacional, com baixa taxa de analfabetismo e alta taxa de escolarização nos ensinos primário, secundário e superior, bem como na duração do estágio educacional obrigatório. Cabe ainda ressaltar a boa infraestrutura do sistema de saúde, do saneamento básico e de sua malha rodoviária que liga as áreas centrais às áreas de produção agrícola.

Assim como as demais regiões da Espanha, a partir da mecanização do trabalho agrícola, Castilla y León enfrenta um processo de desagrarização das áreas rurais, que leva à busca de empregos nas áreas urbanoindustriais com uma grande mobilidade e à saída dos tradicionais moradores dos pequenos povoados, que diminuem a cada dia (Camarero et al., 2016). Nesse sentido, há uma multiplicidade de formas de se relacionar com esses espaços historicamente rurais, diante das condições econômicas impostas pelo desenvolvimento capitalista atual.

O que é importante observamos aqui é que, em ambos os cenários descritos acima, os jovens apresentam diferentes estratégias para levarem à frente seus desejos de futuro, seja no sentido de permanecerem no campo ou mesmo de irem em busca de novas e melhores oportunidades de trabalho e, por que não dizer, de vida.

Os dados quantitativos foram analisados com procedimentos de estatística descritiva, enquanto os dados qualitativos coletados através dos questionários e das entrevistas foram categorizados seguindo o processo de codificação temática proposto por Flick (2007), a partir de Strauss \& Corbin (2002). Esse processo de codificação temática gerou as categorias sobre vinculação dos jovens estudantes com atividades agrícolas; diferenças de gênero no processo de formação e profissionalização, assim como sobre as características, o acesso e a permanência dos jovens nos cursos técnicos em Agropecuária, que passamos a apresentar e discutir.

\section{Resultados e Discussão}

\section{Vinculação de jovens estudantes com atividades agrícolas e diferenças de gênero no processo de formação e profissionalização}

Ao analisarmos a relação dos estudantes com atividades agrícolas, observamos que os jovens pesquisados nos IFs no Brasil diferem dos seus pares espanhóis. Os espanhóis têm uma relação mais direta com as atividades agrícolas - no caso, os rapazes - e estudar uma formação técnica nesse setor tem um sentido de continuação do trabalho familiar. Enquanto $40 \%$ dos pais dos estudantes espanhóis dos centros de formação agrária são proprietários e outros $27 \%$ são parceiros/foreiros ou arrendatários, a situação dos jovens estudantes dos institutos brasileiros mostra que a maioria dos seus pais desenvolve suas atividades 
econômicas fora da agricultura (47\% são trabalhadores assalariados fora da agricultura, $15 \%$ são empresários ou comerciantes nos centros urbanos e $8 \%$ são profissionais liberais) e apenas $27 \%$ são proprietários rurais ou trabalhadores assalariados na agricultura (1\%). Portanto, poucos jovens no curso de Agropecuária nos IFs brasileiros estão vinculados familiarmente com as atividades agrárias e se identificam pessoalmente com elas.

Para a juventude, cujos pais desenvolvem atividades no campo, a condição de proprietários e de viverem na área rural representa uma forte influência na escolha do curso em Agropecuária, principalmente para os rapazes. Segundo suas respostas - e eles poderiam escolher mais de uma opção -, 13\% dos brasileiros e $9 \%$ dos espanhóis afirmaram que a escolha do curso se deu por influência dos pais, mas, desse montante, para 12\% dos brasileiros e $25 \%$ dos espanhóis, a escolha foi uma decisão pessoal, porque gostam de trabalhar com atividades rurais e pretendem permanecer ou substituir os pais nas atividades agrícolas; $10 \%$ dos brasileiros e $13 \%$ dos espanhóis ressaltam a questão de muitas possibilidades de emprego na região onde moram, enquanto $8 \%$ dos brasileiros e $16 \%$ dos espanhóis afirmam que o curso tem tudo a ver com a sua personalidade e sua forma de viver. Assim, família, lugar de origem (identidade) e possibilidades de empregabilidade na região são fortes motivos para a escolha do curso e, a essas características, se soma a oportunidade da formação profissional direcionada para as atividades rurais e a permanência no campo, no caso dos jovens rurais. Essa condição é importante, tendo em vista que os jovens de origem rural são os que mais sofrem influência dos pais proprietários (somente os que são proprietários rurais e não os que são trabalhadores assalariados), e é afirmada como um forte componente da sua decisão pelo curso.

Observa-se que os jovens rurais espanhóis estão mais envolvidos com as atividades agrícolas nas propriedades de seus pais ou familiares (69\%) do que os seus pares brasileiros, apesar de muitos jovens brasileiros (45\%) afirmarem que trabalham na agricultura. Essa situação de trabalho dos jovens rurais espanhóis, matriculados nos centros de formação agrária, pode estar relacionada ao reduzido número de membros da família e ao tipo de agricultura desenvolvida (produção de cereais, gado leiteiro, vinho, etc.). Os dados revelam que, de modo geral, os jovens espanhóis possuem grupo familiar entre dois e quatro membros (92,73\%), situação bem antagônica à dos jovens brasileiros, cujos grupos que possuem mais de cinco membros representam $86,62 \%$, sendo que, destes, $20 \%$ estão formadas por mais de 11 membros. Portanto, a questão da sucessão do patrimônio para os jovens espanhóis aparece como possibilidade mais plausível, principalmente para os rapazes, que são considerados herdeiros naturais da atividade agrícola familiar.

A característica de famílias extensas com limitados recursos econômicos e sociais persiste nas regiões Norte e Nordeste do Brasil. Isso contribui para que os jovens enfrentem várias dificuldades na sucessão e na partilha da terra, empurrando-os para a situação de vulnerabilidade socioeconômica nessas regiões.

Entretanto, em ambos os casos, tanto na Espanha como no Brasil, os rapazes terão mais possibilidades de reproduzir sua identidade de produtor rural do que as moças, que buscarão alternativas, como, por exemplo, um trabalho remunerado fora da agricultura. Há de considerar-se nesse cenário que a proporção de mulheres que terminam os estudos universitários é superior à de homens. Ademais, é preciso salientar que a busca da formação profissional técnica agrícola pelos rapazes está inserida nesse campo de possibilidades de realização pessoal, enquanto as oportunidades para as moças estão mais limitadas pelos papéis tradicionais de gênero, em que as mulheres, nas famílias agricultoras, ocupam o lugar de ajuda e, poucas vezes, são protagonistas nas atividades agrícolas, corroborando os resultados de estudos anteriores (Cruz, 2006).

Além disso, a maior oferta de cursos ligados às atividades urbanas nos centros urbanos próximos, com facilidade de acesso (a maioria dos jovens do campo possui meio de transporte particular na Espanha), aliada às atividades agropecuárias que exigem pouca mão de obra (grandes extensões de terra planas e mecanizadas), fazem com que as moças direcionem seus interesses para as atividades urbanas. No caso dos rapazes, a situação é diferente: a possibilidade da educação técnico-profissional dirigida às atividades agrárias, dentro de uma proposta pedagógica que valorize as identidades rurais, faz com que alguns busquem realizar seus projetos de vida dentro dos espaços rurais. 
As informações prestadas por um jovem, filho de agricultor, 22 anos, estudante do Centro de Formación Agraria "Viñalta" (entrevista J1, Viñalta), ilustram bem essa realidade. Segundo ele, sua família, de quatro membros, vive dos rendimentos das atividades de seu pai, arrendatário de uma parcela de terra para produção de cereais, e dos de sua mãe, tradutora de línguas (devido à sua origem alemã), que possui uma pequena empresa de tradução de línguas. Esse jovem afirma que suas atividades na agricultura (ele trabalha como arrendador de terras na região) se limitam aos finais de semana ou a algum dia da semana quando há folga no Centro de Formação, pois trabalhar com uma atividade que depende mais de maquinários agrícolas do que de trabalho braçal the possibilita se dedicar aos estudos durante a semana e, nos finais de semana, às atividades agrícolas de um proprietário local. Dessa forma, o ganho obtido individualmente como arrendador the garante renda, sem precisar dos recursos da família. Ocasionalmente, ajuda na propriedade arrendada pelo pai, pois essa parcela de terra é maior e demanda maior participação familiar ${ }^{3}$. Ele afirma ainda que a educação recebida no Centro, assim como sua rotina de estudo e trabalho, é fundamental para a realização de seu projeto de futuro, que é permanecer no campo, desenvolvendo atividades agrícolas através das técnicas adquiridas.

Sua irmã, por sua vez, com 25 anos de idade, mora com o namorado numa cidade vizinha com maior infraestrutura. Está cursando o Curso Superior de Comunicação Audiovisual. Apesar de trabalhar, é necessário que os pais colaborem com recursos financeiros para que ela possa se manter em outra localidade e cursar a faculdade, já que o seu emprego não lhe proporciona um ganho financeiro capaz de custear suas despesas pessoais. Assim, as estratégias do grupo familiar, ou das gerações anteriores (geração suporte), são diferentes para filhos e filhas de muitos produtores rurais na Espanha, tendo em vista a realidade vivida em cada contexto. De qualquer forma, o campo de possibilidade de reprodução social de moças e rapazes de origem rural não vão na mesma direção, já que os homens adquirem maior autonomia e individualização financeira primeiro que as mulheres, o que contribui para a permanência no local e nas atividades agrícolas, possibilitando uma realização pessoal dentro do espaço rural, reforçada pela educação adquirida nos Centros de Formação Agrária, ao contrário das moças, que estabelecem suas estratégias em busca de oportunidades na área urbana.

Segundo ele, a juventude, principalmente as moças, está buscando maiores oportunidades de trabalho e renda em atividades não agrícolas, nas cidades ou empresas na região, devido aos baixos salários nas atividades agrícolas ${ }^{4}$, e essa realidade passa a fazer parte cada vez mais do interesse dos jovens. A Revista El Economista Agro (Sereno, 2016) coloca que a Espanha é um dos países da União Europeia com menos jovens agricultores, aproximadamente 4.660 , o que representa menos de $5,4 \%$ do total de agricultores. Um fato que está longe da Alemanha, com 11.600, o que representa entre $7 \%$ e 9,4\% do total, mas que é semelhante na França, com 11.010. A Espanha também difere da Áustria, com 12.430 jovens agricultores, que no total excede 9,4\%, como acontece na Polônia, com 26.650.

Os dados dos questionários mostram que $63,64 \%$ dos jovens espanhóis são residentes no meio rural, em povoados com menos de 10.000 habitantes. Os jovens que se autoidentificam como rurais $(58,33 \%)$ são moradores de povoados com menos de 500 habitantes. Essa observação é corroborada pela pesquisa sobre a população rural na Espanha (Camarero et al., 2009), quando coloca que a diminuição do índice de natalidade e o aumento da emigração de jovens, principalmente de mulheres, nos povoados rurais, têm provocado a masculinização do campo, levando a sérias consequências para a sustentabilidade das antigas relações socioeconômicas de caráter rural. Muitos povoados rurais são formados, na sua maioria, por adultos e, principalmente, homens, produzindo seu desequilíbrio demográfico. Novas ruralidades e novas estratégias passam a ser produzidas

\footnotetext{
${ }^{3}$ Segundo o entrevistado, o acesso à terra pelos pequenos agricultores se dá, geralmente, pelo arrendamento de parcelas de terras de grandes proprietários rurais. O arrendamento da terra se faz por cinco anos através de um contrato que pode ser renovado no final, sendo o pagamento anual.

${ }^{4}$ O município de Tudela de Duero, distante cerca de $15 \mathrm{~km}$ da Província de Valladolid, região produtora de cevada, trigo, batata, girassol, leite, vinho, entre outros, possui aproximadamente 8.582 pessoas, sendo a população de jovens entre 15 e 25 anos de 787 pessoas: 416 homens e 371 mulheres, sendo que aproximadamente 676 jovens estão desempregados (Instituto Nacional de Estatística, 2017).
} 
nesses contextos envelhecidos e masculinizados, nos quais a cidade e seus valores urbanos se aproximam como forma de manter a existência do próprio rural ou da vida no campo. Camarero et al. (2009) colocam, inclusive, o fato de que, no mercado matrimonial, os rapazes permanecentes como herdeiros do patrimônio rural não demonstram ser tão atraentes como os rapazes que conseguem auferir melhores salários na cidade.

Por outro lado, o entrevistado afirma que não gostaria de trabalhar em outra atividade que não fosse a agrícola, pois se identifica com a área agrária e nem tão pouco gostaria de se mudar do seu povoado. Essa também é a posição de $72 \%$ dos rapazes rurais espanhóis pesquisados, mas que divide os rapazes rurais brasileiros (32\% responderam que sim e $32 \%$ que não). As moças, de modo geral, apontam a formação técnica agrícola como a possibilidade de futuramente cursar o ensino superior, conseguir um emprego remunerado e ter acesso a bens de consumo (Pereira, 2004) e a um futuro matrimônio. Isso não representa a priori o interesse de sair do campo, mas a desvalorização das condições do campo como se apresentam para elas. Assim, rapazes e moças vivem a ambiguidade de desejarem estar no meio rural, mas de negarem as imagens negativas que os aproximem de um rural atrasado e precário.

Nesse sentido, o curso técnico-profissional em Agropecuária vai ao encontro de sua perspectiva de futuro, já que amplia o seu campo de possibilidades, pois o entrevistado já possui renda e transporte individualizado, dentro de uma agricultura cada vez menos camponesa e mais mecanizada e profissional (Camarero et al., 2009). Com a formação técnica, a maior parte desses rapazes estarão desenvolvendo suas atividades na propriedade da família, mas é possível que alguns busquem emprego nas propriedades da região ou na agroindústria. Segundo o Gestor do Centro de Formación Viñalta (entrevista G1, Viñalta), há mais procura por técnicos na região do que oferta de mão de obra, uma vez que muitos jovens já possuem a propriedade para desenvolverem seus conhecimentos.

Esse processo de masculinização e urbanização do campo espanhol, como ressalta Camarero et al. (2009), não é um processo novo e nem específico da Europa, como mostram outros autores sobre o rural brasileiro (Abramovay et al., 1998). De modo geral, as transformações, como o processo de desagrarização do campo, parecem atingir diferentemente homens e mulheres, como é o caso da emigração de mulheres e a masculinização do rural, já que os homens que permanecem têm mais dificuldades de contrair matrimônio. Essa realidade não é algo novo no meio rural, pelo contrário, pois, nesse cenário de precarização das condições de reprodução socioeconômica, a profissionalização atinge diferencialmente rapazes e moças, reforçando a função do técnico em agropecuária como uma função masculina, o que, por sua vez, contribui para a iniquidade de gêneros. Isso nos parece uma questão central, pois, de alguma forma, mesmo que, indiretamente, a formação técnica se insere nas estratégias das famílias e das instituições.

É preciso perceber que, em ambos os casos, o trabalho na agricultura é parte do processo de socialização para a construção de uma identidade rural. Com as atividades desenvolvidas no campo, os centros espanhóis reforçam essa identidade ao unirem a formação transmitida e a realidade vivenciada por esses jovens. Esse processo contribui para o estabelecimento de vínculos entre pessoas e as atividades agrícolas, o que não parece ser o caso de todas as mulheres, cujas atividades no meio rural ainda recebem a conotação de "ajuda", como alguém fora do seu lugar. Talvez, esse seja o motivo de observarmos um número tão baixo de moças matriculadas nos centros de formação espanhola: apenas 3\% dos entrevistados. Essa realidade é comprovada nas afirmações das moças rurais de ambos os países que informaram não desenvolver qualquer tipo de atividade rural, sendo que algumas trabalham em comércio nas áreas urbanas, no caso, as brasileiras. Isto é, dizer que não trabalha com as atividades rurais não significa necessariamente que elas não atuam de alguma forma junto às suas famílias, mas que essa participação é menos valorizada por muitos moradores de áreas rurais, empurrando as moças para outras áreas de formação, principalmente no nível técnico.

Podemos observar, portanto, que o Curso de Técnico em Agropecuária nos dois países está diretamente relacionado ao fato de ele apresentar maior atração aos rapazes devido às possibilidades de empregabilidade e permanência em suas regiões de origem, tanto na sua propriedade quanto em propriedades de terceiros ou na agroindústria, reproduzindo 
identidades que colocam moças e rapazes em lugares diferenciados, e as instituições, mesmo que indiretamente, reforçam diferenças de gênero.

De qualquer forma, as instituições pesquisadas ampliam as possibilidades de empregabilidade e renda dos jovens, mesmo que fora do espaço rural. Além disso, como nos coloca Furlani \& Bonfim (2013), ao se inserirem em grupos igualitários, esses jovens ampliam seu autoconhecimento, bem-estar, liberdade, assim como seu sentimento de pertencimento. Nesse sentido, as redes de apoio social que oferecem os centros de formação podem proteger os jovens diante das situações de vulnerabilidade. As políticas públicas, como as educacionais, podem e devem fortalecer a rede de proteção dos jovens rurais diante das diversas vulnerabilidades sociais, com o objetivo de possibilitar a criação de projetos de vida mais estruturados e críticos.

\section{Características, acesso e permanência dos jovens nos cursos técnicos em agropecuária}

As formas com que se dão a entrada e a permanência dos jovens no curso técnico em agropecuária nos distintos países são bem diferentes. No Brasil, a inserção de estudantes ocorre através de processo seletivo em que cada instituição realiza o seu, independente das demais. Em média, são ofertadas de 30 a 40 vagas por curso em cada instituição, cujo único pré-requisito é que o candidato ou candidata tenha concluído o Ensino Fundamental e seja menor de 18 anos de idade.

Os Institutos Federais, assim como as Universidades Federais no Brasil, utilizam um sistema de cotas ( $15 \%$ das vagas) para estudantes oriundos de escolas públicas e com renda comprovada inferior a 1,5 salário mínimo brasileiro, e cotas (10\% das vagas) por etnia-raça para negros, índios e quilombolas (afrodescendentes no Brasil). A procura pelos cursos dos IFs é grande, porque são cursos gratuitos e considerados de boa qualidade; ainda, em muitos casos, são as únicas oportunidades de formação gratuita de nível médio em suas regiões.

Os estudantes contam ainda com o apoio institucional através de uma política de assistência ao estudante (Bolsa de Assistência Estudantil) para atendimento daqueles e daquelas em situação de vulnerabilidade socioeconômica. Esse apoio institucional pode variar dependendo das condições estruturais de cada Instituto. No caso do IFRR, os estudantes podem concorrer a vagas em alojamentos e ao auxílio alimentação (Brasil, 2017b). Já o IFAM oferece bolsas de alimentação, transporte e moradia (Instituto Federal do Amazonas, 2017). E os estudantes em situação de vulnerabilidade do IFAP recebem auxílio a alimentação e transporte, pois o Instituto não conta com alojamento estudantil ou assistência à moradia (entrevista, G1/IFAP).

Esse sistema de cotas e a política de assistência estudantil explicariam, em parte, o interesse de jovens pelo Curso de Técnico em Agropecuária, como uma estratégia de ampliação do campo de possibilidades para que futuramente possam ingressar no nível superior ou mesmo a aquisição de um emprego técnico remunerado na sua região. Entretanto, isso só é possível para os que conseguem concluir o Ensino Médio nesses institutos, tendo em vista o alto índice de evasão escolar, como mostra o estudo de Narciso (2015).

Narciso (2015) chama a atenção para as dificuldades de acesso a dados sobre repetência e evasão escolar nos IFs, pois esses dados não estão disponíveis em canais oficiais. Para o ano de 2013, segundo a autora, a média da taxa de abandono escolar nos IFs foi de $8,6 \%$. Comenta ainda que uma fiscalização realizada pelo TCU (Tribunal de Contas da União) com 38 instituições federais apontou uma taxa de evasão de 18,9\% nos cursos feitos por estudantes que acabaram de completar o Ensino Médio, ou seja, a modalidade subsequente. "Entre os alunos que fazem cursos técnicos concomitantemente e integralmente com o ensino médio, a evasão foi menor: 6,4\%. A taxa de conclusão é de $31,4 \%$ e $46,8 \%$, respectivamente" (Narciso, 2015, p. 87).

O problema da evasão escolar nos IFs, no Brasil, tem sido tratado como uma consequência da forma como se deu o processo de expansão dos mesmos, pois, em pouco 
mais de 10 anos $^{5}$, foram criados mais de 440 campi, uma expansão histórica, de larga escala e em alta velocidade, o que gerou um descompasso, principalmente devido à falta de professores e técnicos.

Os dados do Relatório Educação para Todos no Brasil 2000-2015 (Brasil, 2014a), que serviram de base para o Plano Nacional de Educação 2014-2014 (PNE) (Brasil, 2014b), por sua vez, revelam que o maior contingente da rede federal de ensino técnico-profissional são mulheres jovens que nem sempre estão interessadas em cursos profissionalizantes na área de agrárias, principalmente na região Norte do Brasil. Assim, a evasão escolar deve atingir preferencialmente as mulheres que não percebem os cursos de agrárias vinculados com os seus projetos de vida, mas que se utilizam dos mesmos para chegar ao curso desejado, no momento oportuno, dentro dos próprios IFs.

A possibilidade de mudança de curso, e mesmo de área, tem acontecido depois que a juventude ingressa nos IFs. No caso específico do Curso de Técnico em Agropecuária, este tem servido de via de acesso para outros cursos com perfil urbano-industrial, estratégia muito utilizada por jovens de áreas urbanas ou de áreas localizadas entre as fronteiras rural/urbano. Isto é, nem todos os jovens, rapazes e moças, que optam pelo curso de Técnico em Agropecuária se identificam com o curso, mas apenas com a possibilidade de conseguirem uma vaga nos IFs. Essa prática, por sua vez, limita as oportunidades da juventude rural que, teoricamente, se identifica com as atividades agrícolas por já estar inserida no mundo rural. Porém, as escolas de Ensino Fundamental de origem desses jovens oferecem piores condições estruturais de partida para conseguirem uma vaga nos Institutos, principalmente nos cursos da área de agrárias. Em outras palavras, se os jovens rurais se identificam com o Curso de Técnico em Agropecuária dessas Instituições, por sua vez, essa identificação das Instituições com a realidade desses jovens deixa a desejar.

Essa competição por vagas entre juventude rural e urbana pelos Cursos de Técnico em Agropecuária nos IFs tende a presentar sérios descompassos com a realidade das diferentes juventudes. Segundo o Diretor do Departamento de Ensino do Instituto Federal de Educação, Ciência e Tecnologia do Amapá do campus Porto Grande (entrevista G3, IFAP), a partir de 2017, foi adotado o método de análise de desempenho para o ingresso dos estudantes no Ensino Médio integrado e, subsequentemente, no Instituto. O candidato, ao se escrever, disponibiliza suas notas no Ensino Fundamental II (do $6^{\circ}$ ao $9^{\circ}$ ano) num formulário eletrônico e o sistema faz a seleção dos 40 alunos, tendo os melhores classificados a sua matrícula efetivada. Esse processo seletivo não exige conhecimentos ou aptidões específicas dos candidatos, colocando todos em igualdade de competição, mas não leva em consideração as condições de partidas que não são equilibradas ${ }^{6}$. Essa política de meritocracia, de qualquer forma, facilita a inserção dos jovens urbanos que tiveram melhores oportunidades de acesso à educação fundamental, ao mesmo tempo em que dificulta o acesso daqueles "menos preparados", no caso, os jovens rurais, que enfrentam as dificuldades de infraestrutura da educação nos espaços rurais e que estão mais vinculados às atividades do campo. É interessante que estava prevista no Plano de Expansão da Rede Federal de Educação Profissional e Tecnológica a

[...] preferência por cidades com baixo Índice de Desenvolvimento Humano (IDH), principalmente no interior do País e periferias das grandes cidades, levando sempre em conta as potencialidades de desenvolvimento social e a proximidade com os Arranjos Produtivos Locais (APL) (p.52).

Contudo, a política de acesso dos jovens à educação profissionalizante parece excluir os jovens rurais quando não prioriza sua identificação com o curso de Agropecuária. Essa situação reforça as palavras de Stropasolas (2014), quando afirma que as políticas e programas das instituições oficiais dirigidas aos jovens rurais, além de insuficientes, são, em

\footnotetext{
${ }^{5}$ No ano de 2008, através da promulgação da Lei n. ${ }^{\circ} 11.892 / 2008$, são criados os Institutos Federais de Educação, Ciência e Tecnologia (IFETs), aglutinando 31 CEFETs, 75 unidades descentralizadas (UNEDs), 39 Escolas Agrotécnicas, sete Escolas Técnicas federais e oito escolas vinculadas às universidades.

${ }^{6}$ Segundo o informante, esse processo já vem sendo adotado pelos IFs, como é o caso dos Institutos de Brasília e Roraima.
} 
certos casos, inadequados, quando contemplam, sobretudo, os jovens que possuem maior capital social, econômico e político.

Em relação à escolha do curso e à identificação com a formação agropecuária, se agruparmos os cursos que, de alguma forma, estão vinculados à área de agrárias e os jovens que representam interesse de mudar de curso para outras áreas ou não sabem que curso desejam, teremos $16,90 \%$ dos respondentes que pretendem se manter no curso de Técnico em Agropecuária ou trocar para outro relacionado à área de agrárias e possivelmente continuar o curso superior na mesma área. Entretanto, 58,45\% dos jovens pesquisados gostariam de mudar de curso e possivelmente cursar uma universidade em área diferente da área de agrárias e $24,65 \%$ não sabem (ou não têm certeza do que desejam enquanto profissão) ou simplesmente não responderam. E se separamos os $16,90 \%$ que pretendem se manter no curso ou na área, teremos $12,25 \%$ que se autoidentificam como rurais, principalmente rapazes, e 4,65\% deles acreditam que o curso Técnico em Agropecuária Ihes possibilita chegar à Universidade. Portanto, a maioria dos jovens $(58,45 \%)$ matriculados no curso técnico em Agropecuária nos IFs não desejam continuar no curso e apenas os jovens rurais $(16,90 \%)$ se sentem atraídos pela formação profissional na área de agrárias.

Os jovens entrevistados apontam também dificuldades em acompanhar o projeto pedagógico dos cursos, já que muitos deles e delas vêm de uma carência no ensino básico. E, por outro lado, muitos estão em situação de vulnerabilidade socioeconômica, o que explicaria, em parte, a evasão dos estudantes das áreas rurais. Quando questionados sobre essas dificuldades no curso de Agropecuária, sendo que os jovens rurais poderiam escolher mais de uma resposta, as respostas mais frequentes, conforme a Tabela 1, foram:

Tabela 1 - Dificuldades para Cursar o Curso de Agropecuária

\begin{tabular}{|c|c|c|c|c|}
\hline \multirow{2}{*}{$\begin{array}{l}\text { País } \\
\text { Sexo }\end{array}$} & \multicolumn{2}{|c|}{ BRASIL } & \multicolumn{2}{|c|}{ ESPANHA } \\
\hline & Rapazes & Moças & Rapazes & Moças \\
\hline Respostas & $(\%)$ & $(\%)$ & $(\%)$ & $(\%)$ \\
\hline $\begin{array}{l}\text { Distância entre o local onde moram e o Instituto ou } \\
\text { Centro }\end{array}$ & 27 & 14 & 31 & 10 \\
\hline A dificuldades financeiras da família & 11 & 05 & 03 & 00 \\
\hline $\begin{array}{c}\text { As matérias são difíceis, os alunos têm dificuldades } \\
\text { em acompanhar os professores e colegas }\end{array}$ & 11 & 05 & 17 & 00 \\
\hline $\begin{array}{l}\text { Dificuldade da permanência em tempo integral nos } \\
\qquad \text { Institutos }\end{array}$ & 07 & 00 & 03 & 00 \\
\hline A desorganização da escola & 00 & 05 & 20 & 10 \\
\hline A rigidez das normas da Escola & 00 & 02 & 11 & 02 \\
\hline A desmotivação dos professores & 00 & 02 & 09 & 02 \\
\hline A desmotivação dos colegas & 02 & 05 & 06 & 03 \\
\hline $\begin{array}{l}\text { Não se veem realizados pessoalmente em Téc. em } \\
\text { Agropecuária }\end{array}$ & 00 & 07 & 03 & 00 \\
\hline Outras dificuldades ou não souberam responder & 07 & 00 & 06 & 00 \\
\hline
\end{tabular}

Fonte: Dados de pesquisa.

Tanto para os jovens brasileiros como para os jovens espanhóis, a distância entre o local onde moram e o Instituto ou o Centro aparece como a maior dificuldade para permanecerem na escola. Contudo, observamos no estacionamento do Centro de Viñalta que muitos estudantes espanhóis possuíam transporte próprio e que, segundo entrevistas, tinham a estratégia de trocarem caronas semanais, isto é, revezavam entre eles de forma a diminuir os 
gastos com combustível. De qualquer forma, as dificuldades financeiras da família atingem mais os jovens brasileiros. Um fato comum é que tanto brasileiros como espanhóis citam as matérias em ambas as instituições como difíceis, assim como acompanhar os professores e colegas no desenvolvimento das mesmas. Este fato é apontado mais pelos rapazes e parece coincidir com a tendência atual de melhor adaptação das mulheres às demandas acadêmicas do sistema de ensino formal. É interessante observarmos aqui que algumas moças brasileiras não se veem realizadas como Técnico em Agropecuária, condição que não parece significativa para o universo das respostas dos rapazes.

Outro ponto importante a destacar é o tempo de permanência dos jovens nos cursos, que está relacionado com a dificuldade de permanência integral no centro, a qual é sinalizada principalmente por rapazes. Aqui se observa uma diferença significativa de gênero, pois nenhuma das moças indica problema para a permanência integral no centro, o que pode significar que os rapazes têm mais dificuldades para compatibilizar os estudos com uma ocupação laboral ou com o trabalho na agricultura familiar, enquanto as moças têm mais apoio familiar para uma dedicação completa aos estudos. Nos diferentes Centros de Formación Agrária na Espanha, o tempo de formação é de 2.000 horas em tempo integral, o que corresponde a dois anos. Já no Brasil, o tempo de permanência é maior. Segundo um Gestor (entrevista, G1/IFAP), a carga horária mínima exigida pelo Ministério da Educação é de 2.400 horas, o que corresponde a três anos de curso. Verificamos nos Programas Políticos de Cursos (PPCs) dos três cursos pesquisados que a carga horária está em torno de 3.700 horas em tempo integral: IFAP (3.982 horas), IFAM (4.040 horas) e IFRR (3.360 horas). Portanto, os estudantes brasileiros permanecem muito mais tempo que os espanhóis nas instituições e isso tem impactos sobre a dinâmica da agricultura familiar, pois eles se afastam das atividades agrícolas familiares, assim como dificulta sua obtenção de emprego fora da agricultura familiar na região, o que pesa sobre a decisão de permanecer no Instituto pelo tempo exigido. Nos Centros de Formación Agrária na Espanha, no nível médio, o título é de Técnico em Produção Agropecuária ${ }^{7}$ e corresponde ao nível médio técnico em Agropecuária no Brasil.

Os centros contam com recursos públicos da Comunidade Autônoma de Castilla y León e cada um possui flexibilidade para adequar seus projetos pedagógicos à realidade dos diferentes contextos em que estão inseridos, apesar da existência de módulos comuns. Cada centro conta com serviços de alimentação e hospedagem, custeados, em parte, por recursos públicos e, em parte, pelas famílias dos estudantes, no valor de 1,5 salário mínimo da Espanha por ano. Esses centros possuem atividades produtoras que se revertem em recursos financeiros, através do Conselho de Educação da Província, para manutenção dos mesmos. Diferentemente do Brasil, os centros não possuem bolsas de apoio aos estudantes, como transporte, auxílio moradia, auxilio alimentação, etc.

Segundo depoimentos do Gestor de "La Santa Espina" (entrevista G2), os centros possuem um baixo nível de evasão escolar, em torno de um a dois estudantes por turma, e mudanças de curso ou de área são consideradas excepcionais, já que a maioria dos(as) estudantes é proveniente de áreas rurais e são pessoas vinculadas familiarmente com as atividades agrícolas. Entretanto, é importante destacarmos que, na Região de Castilla y Léon, havia oito escolas com formação na área de agrária, mas esse número vem diminuindo e hoje são apenas cinco escolas. Um dos motivos apresentados pelos entrevistados para o fechamento das instituições é a baixa procura pela área de agrárias, tendo em vista que há cada vez menos jovens nos povoados da região.

Quando questionados se gostam de cursar Agropecuária ou gostariam de trocar de curso, $12,73 \%$ dos jovens espanhóis afirmaram que não mudariam de curso porque possuem identidade com a área rural ou atividades rurais; outros 5,45\% gostariam de fazer futuramente o curso de Médico Veterinário; 3,64\% pretendem fazer um curso superior em Engenharia Florestal, e 1,82\% gostaria de investir seus conhecimentos em Agroecologia. Porém, mais de $50 \%$ dos jovens matriculados nos cursos de Técnico em Agropecuária dos centros espanhóis pesquisados não têm muita certeza da escolha que fizeram pelo curso. Mais uma vez, os que mais demonstraram ter certeza da escolha pela área de agrária são os/as jovens que se autoidentificaram como rurais (23,64\%). O que nos parece responsável

\footnotetext{
${ }^{7}$ O centro de Formação em Agropecuária possui grau médio e superior em Técnico em Agropecuária.
} 
por essa situação é o fato de o curso não representar uma mudança significativa na sua condição socioeconômica, principalmente para os 50\% que não responderam ou não souberam responder. $O$ curso representa para muitos apenas o cumprimento da exigência de uma etapa escolar, pois, em posse de um certificado de Ensino Médio, esses e essas jovens podem buscar oportunidades de emprego na área de serviços ou industrial.

De qualquer forma, tanto os cursos dos IFs como os dos Centros de Formação Agrária na Espanha são considerados, pelos estudantes, de boa qualidade: $47,89 \%$ dos brasileiros e $60 \%$ dos espanhóis classificam os cursos como bons, e $41,55 \%$ dos brasileiros e $20 \%$ dos espanhóis afirmam que os cursos são excelentes ${ }^{8}$. A justificativa então pelo interesse de alguns para a mudança de curso - dos jovens e das jovens brasileiras - está no fato de que eles e elas "não se identificam com o curso ou a área, mesmo reconhecendo a qualidade dos professores e do curso em geral".

No caso das moças, um desses motivos está relacionado ao perfil masculino do curso, destacando a característica de gênero nos projetos formativos das instituições. Ao analisarmos os dados dos estudantes dos Cursos de Agropecuária dos centros de formação na Espanha, podemos observar que se trata de cursos que também atraem mais os homens que vivem nos povoados de tradição rural. Como comentamos anteriormente, nos dados sobre o perfil dos estudantes no Curso Técnico de nível médio em Agropecuária da Espanha, chama a atenção a baixa procura de moças por essa formação. Entretanto, é importante salientar, como nos foi informado pelo gestor de um dos centros, que o número de moças é maior no Curso Superior em Agropecuária.

Para os entrevistados de Brasil e Espanha, o perfil do curso de técnico em agropecuária no nível médio tem um sesgo masculino, pois afirmam que o mercado de trabalho facilmente absorverá os rapazes, o mesmo não sendo verificado nas respostas das moças. Observa-se a reprodução da segregação horizontal do mercado de trabalho por motivos de gênero e as respostas apontam a existência de preconceito em relação ao exercício da profissão pelas mulheres, reproduzindo a necessidade de que as mulheres tenham de adaptar-se às condições de trabalho e às expectativas criadas para os trabalhadores homens (Cruz, 2006; Maruani, 2002). Apesar de responderem que o mercado favorece a moças e rapazes igualmente (62,94\%), 34,01\% dos rapazes entrevistados afirmaram que a profissão é mais apropriada aos homens, porque exige esforço físico, mas que as mulheres poderão exercê-la se possuírem "aptidão", "se tiverem interesse pela área", "se estiverem bem preparadas". São os rapazes rurais (12 espanhóis e 8 brasileiros) que mais enfocam a necessidade de força física e preparo para o exercício da profissão. Algo que dificulta, segundo eles, que as mulheres exerçam a profissão. Esse discurso reforça a divisão sexual do trabalho e a imagem de que as mulheres não podem exercer atividades consideradas masculinas se não demonstrarem qualidades atribuídas historicamente ao universo masculino, como força, aptidão e preparo físico.

Das 13 moças rurais participantes da pesquisa (11 brasileiras e duas espanholas), 11 responderam não desenvolver qualquer atividade no meio rural, sendo que sete não possuem qualquer interesse em vir a desenvolvê-la; duas informaram que sim, mas que não têm interesse em continuar no curso técnico agrícola, e apenas uma moça, mesmo não desenvolvendo atividades agrícolas no momento, pretende fazer uma faculdade de Agronomia. Já as 49 moças de áreas urbanas matriculadas no Curso de Agropecuária nos Institutos brasileiros, apesar de afirmarem não possuir origem rural, são as que menos buscam continuar na formação em Técnico de Nível Médio em Agropecuária, mas possuem o interesse num curso superior na área de agrária, devido ao fato de que a atuação do profissional é percebida como um trabalho intelectual, de gestão, e menos de esforço físico, características consideradas femininas. Para essas moças, a oportunidade de estarem num Curso Técnico nos IFs somente amplia as possiblidades de chegarem ao curso superior, mesmo que não seja na área de agrária, e maiores oportunidades de empregabilidade nas empresas e indústrias da região Norte do Brasil. Aqui, ficam evidentes as diferentes estratégias de gênero para realizarem seus projetos de futuro, mas as incertezas parecem ser

${ }^{8}$ 9,15\% dos brasileiros e brasileiras consideram ainda o curso regular e 1,41\% não respondeu. Já 16,36\% dos espanhóis e espanholas consideram o curso regular, seguidos de $3,64 \%$ que consideram ruim ou péssimo. 
maiores para as moças tendo em vista que seus projetos se direcionam para o mundo urbano e não contam com a propriedade da família para realização pessoal.

Assim, se os cursos da área de agrárias no Brasil apresentam mais mulheres do que os cursos na Espanha, isso não pode ser entendido como se as mulheres no Brasil tivessem mais interesse e oportunidades nessa área do que as espanholas. Essa perspectiva é reforçada pela conversa com professores e gestores dos centros na Espanha. Para o gestor (entrevista G1, Viñalta), é mais comum encontrarmos moças no curso técnico de nível médio em Agroecologia e no superior de Agropecuária por serem cursos com perfis que envolvem mais a atividade intelectual. De qualquer forma, a realidade da juventude rural, seja no Brasil ou na Espanha, aponta para a complexidade das experiências vividas. Essas experiências, por sua vez, ajudam a redefinir as identidades sociais desse público. Como aponta Stropasolas (2014, p.180), "por não visualizar mudanças na sua condição social, parcela expressiva da juventude vem recusando reproduzir a profissão de agricultor(a), sobretudo, as moças trabalhar no campo".

\section{Conclusões}

Acreditamos que existe uma pluralidade de respostas, de caminhos possíveis, diante das incertezas que geralmente marcam os projetos de vida dos jovens quanto ao seu futuro. Um futuro que aparece com maiores incertezas quando a relação entre identidade, educação e trabalho está inserida nos projetos de educação dos cursos de formação profissional. Por sua vez, o lugar que o/a jovem ocupa numa determinada sociedade e as características dessa sociedade podem ajudar a definir suas respostas diante das condições ou possibilidades que se vislumbram à sua frente no processo de elaboração de seus projetos de futuro. Não há um único caminho a ser trilhado. $E$, nesse caso, a educação, principalmente a educação técnicoprofissional, dever ser um forte componente de ascensão social para os/as jovens rurais, mesmo para aqueles ou aquelas que não desejam permanecer no campo.

A educação técnico-profissional em agropecuária tem um papel fundamental na valorização da identidade rural desses jovens estudantes, reforçando sua ruralidade, principalmente ao distanciar a formação técnica em agropecuária de um rural atrasado, tradicional e resistente à incorporação de novas formas de produzir e exigir. Ao incorporar o novo, os jovens relativizam os questionamentos da sua identidade rural diante da urbanormatividade e passam a sentir o rural como parte importante do seu processo de formação profissional, reprodução social e valorização da sua cultura.

A diluição das fronteiras campo/cidade vem desconstruindo antigas visões de espaços opostos, algo que também começa a ser questionado quando a preferência pela vida no campo é percebida pela juventude rural como "qualidade de vida", "vida saudável", longe da violência e do individualismo das sociedades urbanoindustriais. Mas é também um lugar de dificuldades de todo tipo. Portanto, as respostas que essa juventude rural dá às situações vividas são a manifestação das ambiguidades exigentes. Nesse sentido, as instituições de ensino - ao incorporar nos projetos educacionais as questões relacionadas à realidade desses jovens e as suas diferenças de gênero, ampliando suas oportunidades de formação - são parte fundamental da elaboração e execução dos projetos de vida dos jovens rurais. Mas é preciso que os cursos incorporem uma perspectiva de gênero que socialize para a equidade entre mulheres e homens, assim como leve em conta a realidade da dinâmica da agricultura familiar, propondo projetos pedagógicos com menor carga horária e maior flexibilidade de funcionamento.

Apesar das incertezas de muitos jovens quanto ao seu futuro, essas incertezas demonstram ser ainda maiores entre os jovens rurais brasileiros, tendo em vista a lógica que vem sendo adotada pelos IFs no processo seletivo para o Curso Técnico em Agropecuária e na permanência dos jovens nas instituições pesquisadas, ao não levar em consideração as suas condições de vida, a sua identidade rural e as suas necessidades de trabalho e renda. Assim, numa dinâmica movida pela lógica da meritocracia, esses jovens competem de forma desigual com seus pares urbanos, pois, por terem as piores oportunidades de formação fundamental, dificilmente conseguirão ocupar as vagas direcionadas à formação técnicoprofissional na área de agrárias. 
No caso dos jovens rurais espanhóis, as incertezas parecem se diluir quando se inserem nos Centros de Formación Agrária, preferencialmente dirigidos aos jovens de áreas agrárias. Ademais, os Centros, ao incorporarem as questões que envolvem a realidade desses jovens, oferecem-lhes uma infraestrutura capaz de fazer frente às suas necessidades de permanência e de estudo desses jovens.

Apesar de não ser o objetivo deste estudo analisar os programas de formação oferecidos pelas diferentes instituições, só pelo tempo de permanência dos jovens exigido por cada uma delas, já se demonstra uma defasagem, no caso do Brasil, entre a realidade e as intenções dos jovens rurais e o Projeto Pedagógico de Curso. Além disso, em ambas as instituições pesquisadas (Brasil e Espanha), verificamos que a formação apresenta um forte simbolismo de gênero, o que reforça a ideia de que a formação técnico-profissional em agropecuária está direcionada ao público masculino. E isso aparece nas entrevistas dos jovens, quando colocam que o mundo das atividades rurais é "pesado", que os homens têm mais condições de exercê-las. Porém, quando observamos que, mesmo para as jovens estudantes dos IFs que estão cursando o Técnico em Agropecuária, essa etapa serve de acesso às Universidades Federais Brasileiras nos cursos de agrárias, de forma a se inserirem futuramente no mundo do trabalho rural com outro status profissional e uma maior respeitabilidade dos seus pares masculinos e de seus familiares.

\section{Referências Bibliográficas}

Abramovay, R., Silvestro, M., Cortina, N., Baldissera, I. T., Ferrari, D., \& Testa, V. M. (1998). Juventude e a agricultura familiar: desafios dos novos padrões sucessórios. Brasilia: Unesco.

Barros, L., Santos, M. A., Bock, S. D., \& Machado, V. M. (2015). Campo de experiência: projeto de vida. In M. A. Santos, R. Ladeia (Orgs.), Fortalecendo projetos de vidaNocação (1. ed.). São Paulo: Ação Comunitária do Brasil.

Bauman, Z. (2000). Trabajo, consumismo y nuevos pobres. Barcelona: Editorial Gedisa.

Benito, C. G., \& Mendez, C. D. (2009). La juventud rural en el cambio de siglo: tendencias y perspectivas. Revista de Estudios de Juventud, 87, 125-144.

Bourdieu, P. (1996). Razões Práticas: sobre a teoria da ação. (Trad. Maria Corrêa, 9. ed.). Campinas: Papirus.

Bozon, M. (1995). Amor, Sexualidade e Relações Sociais de Sexo na França Contemporânea. Estudos Feministas, 3(1), 122-135.

Brasil. Ministério da Educação e Cultura (2014a). Brasil Relatório Educação Para Todos 2000-2015. Recuperado em 16 de outubro de 2015, de

http://portal.mec.gov.br/index.php?option=com_docman\&view=download\&alias=15774-ept-relatorio$06062014 \&$ Itemid=30192

Brasil. Câmara dos Deputados (2014b). Plano Nacional de Educação 2014-2024 (Série Legislação). Brasilia. Recuperado em 16 de outubro de 2015, de http://www.observatoriodopne.org.br/uploads/reference/file/439/documento-referencia.pdf

Brasil. Ministério da Educação. Coordenação Geral de Informações e Análises Epidemiológicas - CGIAE (2017a). Mortalidades. Recuperado em 15 de jun. de 2017, de http://portalsaude.saude.gov.br/index.php/o-ministerio/principal/secretarias/svs/mortalidade

Brasil. Ministério da Educação. Secretaria de Educação Profissional e Tecnologia. (2017b). Edital no 03/2016. Recuperado em 14 de jun. de 2017, de http://www.ifrr.edu.br/campi/amajari/processo-seletivo/cursostecnicos-integrados-ao-ensino-medio/ano-2016.2/2017.1/edital-de-convocacao-no-03-2017

Camarero, L., Cruz, F., \& Oliva, J. (2016). Rural sustainability, inter-generational support and mobility. European Urban and Regional Studies, 23(4), 734-749.

Camarero, L., Cruz, F., González, M., Del Pino, J., Oliva, J., \& Sampedro, R. La población rural de España: De los desequilibrios a la sostenibilidad social (Colección Estudios Sociales, 27). Barcelona: Fundación La Caixa, 2009.

Carneiro, M. J., \& Castro, E. G. (Org.). (2007). Juventude rural em perspectiva. Rio de Janeiro: Mauad X.

Castro, E. G. (2009). Juventude Rural no Brasil: processos de exclusão e a construção de um ator político. Revista Latinoamericana em Ciencias Sociales, Niñez y Juventud, 7(1), 179-208. Recuperado em 19 de dezembro de 2018, de http://revistaumanizales.cinde.org.co/rlcsnj/index.php/RevistaLatinoamericana/article/view/223

Cruz, F. (2006). Género, psicología y desarrollo rural: la construcción de nuevas identidades para las mujeres en el medio rural (Serie Estudios). Madrid: Ministerio de Agricultura, Pesca y Alimentación. 
EUR-Lex. (2014). Acess to European Union Law. Recuperado em 26 de junho de 2017, de http://eurlex.europa.eu/legal-content/pt/TXT/?uri=CELEX:52014PC0478

Flick, U. (2007). Introducción a la investigación cualitativa (2a ed.). Madrid: Ediciones Morata.

Furlani, D. D., \& Bonfim, Z. A. C. (2013). Jovens de ambiente rural e urbano e sua relação com projetos de vida. In J. F. Leite \& M. Dimenstein (Orgs.). Psicologia e contextos rurais (pp. 117-143). Natal: EDUFRN.

Greene, J. C. (2007). Mixed methods in social inquiry. San Francisco: John Wiley \& Sons.

Greene, J. C. (2008). Is Mixed Methods Social Inquiry a Distinctive Methodology? Journal of Mixed Methods Research, 2(1), 7-22.

Harding, S. (1996). Revista Ciencia y Feminismo. Madrid: Morata.

Hernández, O. A. (2000). El Desarrollo Profesional Creador (DPC) como dimensión del proyecto de vida en el ámbito profesional. Revista Cubana de Psicologia, 19(2), 106-114. Recuperado em 16 de outubro de 2015, de www.clacso.org/

Instituto Brasileiro de Geografia e Estatística - IBGE. (2010). Censo Demográfico 2010. Recuperado em 11 de novembro de 2015, de http://www.brasileirosnomundo.itamaraty.gov.br/a-comunidade/estimativaspopulacionais-das-comunidades/estimativas-do-ibge/censo-demografico-ibge-2010.pdf

Instituto Federal do Amazonas - IFAM. (2017). Programa Socioassistencial. Brasília. Recuperado em 14 de junho de 2017, de http://www2.ifam.edu.br/pro-reitorias/ensino/proen/assistencia-estudantil/psicologia

Instituto Nacional de Estatística - INE. (2017). Padrón. Población por municípios. Demografia y Población. Recuperado em 05 de julho de 2017, de http://www.ine.es/dyngs/INEbase/es/categoria.htm?c=Estadistica_P\&cid=1254734710990

Jurado, C., \& Tobasura, I. (2012). Dilema de la juventud en territorios rurales de Colombia: ¿campo o ciudad? Revista Latinoamericana de Ciencias Sociales. Niñez y Juventud, 10(1), 63-77.

Lagarde, M. Género y feminismo - Desarrollo Humano y Democracia. Madrid: Horas y Horas. 1996.

Lopes, L. G. R., \& Carvalho, D. B. (2015). Temporal do Assentamento e os Projetos de Vida da Juventude Rural. Revista de Economia e Sociologia Rural, 53(4), 571-588.

Maruani, M. (2002). Trabajo y el Empleo de las Mujeres. Madrid: Editorial Fundamentos.

Narciso, L. G. S. (2015). Análise da Evasão nos Cursos Técnicos do Instituto Federal do Norte de Minas Gerais Campus Arinos: exclusão da escola ou exclusão na escola? (Dissertação de mestrado em sociologia política). Universidade Federal de Santa Catarina, Centro de Filosofia e Ciências Humanas, Florianópolis.

Organização das Nações Unidas. Programa das Nações Unidas para o Desenvolvimento - PNUD (2016). Índice de Desenvolvimento Humano. New York: PNUD.

Pereira, J. L. G. (2004). Juventude rural: para além das fronteiras entre campo e cidade (Tese de doutorado em Desenvolvimento, Sociedade e Agricultura). Universidade Federal Rural do Rio de Janeiro, Rio de Janeiro.

Scott, J. (1986). Gender: A useful category of historical analysis. The American Historical Review, 91(5), 10531075.

Sereno, E. (2016, 23 fevereiro). Formación para jóvenes agricultores: escasa y alejada de Europa. Revista El Economista Agro. Retrieved em 24 de fevereiro de 2017, de http://www.eleconomista.es/aragon/noticias/7369217/02/16/Formacion-para-jovenes-agricultoresescasa-y-alejada-de-Europa.html

Strauss, A. L., \& Corbin, J. (2002). Bases de la investigación cualitativa: técnicas y procedimientos para desarrollar la teoría fundamentada. Medellín: Universidad de Antioquia.

Stropasolas, V. L. (2006). O mundo rural no horizonte dos jovens. Florianópolis: Editora da UFSC.

Stropasolas, V. L. (2014). A dimensão da diversidade social na concepção de políticas públicas para a juventude rural. In M. A. Menezes, V. L. Stropasolas \& S. B. Barcellos (Orgs.), Juventude rural e políticas públicas no Brasil. Brasília: Presidência da República.

Velho, G. (1987). Individualismo e cultura (2. ed.). Rio de Janeiro: Jorge Zahar Editor.

Wood, D., Bruner, J. S., \& Ross, G. (1976). The role of tutoring in problem solving. Journal of Child Psychology and Psychiatry, and Allied Disciplines, 17, 89-100.

Data de submissão: 5/Jun./2018.

Data de aceite: 29/Dez./2019

Classificação JEL: Z13, Z19. 